\title{
Contraception in crisis
}

\author{
Meera Kishen, Toni Belfield
}

\section{Background}

At least $50 \%$ of pregnancies in the UK are unplanned and approximately one-fifth of conceptions end in legal abortion despite over $70 \%$ of women in the age range 16-49 years using some form of contraception. ${ }^{1}$ Despite free availability of family planning services in the UK, unplanned and unwanted pregnancies remain a public policy issue. It is therefore necessary that current contraceptive service provision be examined in terms of access, choice and quality.

The public health benefits and cost effectiveness of family planning provision are long established. ${ }^{2}$ Policy Studies Institute studies ${ }^{3}$ have confirmed the economic value of family planning provision as early as 1982 . In the UK, contraceptive advice and supplies have been provided free since the mid-1970s through multiple outlets including general practice, specialist community clinics, the voluntary sector and, more recently, pharmacies. The National Health Service (NHS) is committed to the concept of client choice and empowerment, which is particularly relevant in contraception where informed decision-making is paramount in achieving effective contraceptive practice. The Teenage Pregnancy Strategy, ${ }^{4}$ the National Strategies for Sexual Health and HIV in England and Wales, 5,6 Respect and Responsibility in Scotland, ${ }^{7}$ the National Standards for Sexual Health Services ${ }^{8}$ and the Public Health White Paper Choosing Health ${ }^{9}$ have clearly acknowledged the importance of contraception in addressing sexual health with a holistic approach. However, despite the stated aims of these national strategies, currently it appears that even the existing contraceptive service provision within the NHS is being compromised.

\section{Current situation}

A Taylor Nelson Sofres survey ${ }^{10}$ published in 2004 raised serious concerns about the state of contraception provision. Clinicians reported restricted access to new and long-acting reversible methods of contraception (LARC), great variation in access to abortion services, closure of specialist community clinics, and restricted availability of training in contraception and sexual health care. They also reported clients, including young people, being turned away from open-access, walk-in community clinics due to poor staffing levels and overwhelming demand.

The National Institute for Health and Clinical Excellence (NICE) Clinical Guidance published in 2005 on provision of LARC $^{11}$ provides clear evidence-based

\section{J Fam Plann Reprod Health Care 2006; 32(4): 211-212}

Faculty of Family Planning and Reproductive Health Care, London, UK

Meera Kishen, MD, FFFP, President

fpa, London, UK

Toni Belfield, BSc, FRSH, Director of Information

Correspondence to: Dr Meera Kishen, Faculty of Family Planning and Reproductive Health Care, 27 Sussex Place, Regent's Park, London NW1 4RG, UK.

E-mail: meera.kishen@ntlworld.com analysis of their clinical and cost effectiveness. The Economics of Sexual Health, ${ }^{12}$ also published in 2005, further reinforces the cost benefits of providing contraceptive services. This research illustrated that the NHS in England could save almost $£ 1$ billion over 15 years by investing in contraceptive services and speeding up women's access to abortion services by just 10 days. Key findings show that by changing contraceptive prescribing patterns and raising the profile of different methods of contraception, the number of unintended pregnancies would fall and the costs incurred by abortion and maternity services would be cut by $£ 500$ million over 15 years, resulting in annual savings of around $£ 33$ million. It is clear from all available evidence that the cost of making a full range of contraceptive methods available to a given population is far outweighed by the savings to health and social service budgets achieved by the avoidance of unplanned pregnancy.

To enable women to use contraceptive methods safely and effectively the prerequisites of method choice and ease of access are fundamental. In addition, appropriately trained providers are required. General practice remains the mainstay of contraceptive provision in the UK. The General Medical Services contract negotiated after the publication of the National Sexual Health Strategy offers few incentives to increase service provision or improve quality of contraception and sexual health services in general practice. There is still no requirement for nationally accredited training to provide basic contraceptive services by general practice teams despite the fact that they see around $80 \%$ of all contraceptive consultations. Contraception provision in general practice remains heavily weighted towards the more user-dependent, oral contraceptive methods with very few practices with a special interest in contraception providing the more effective intrauterine devices, intrauterine systems and subdermal implants (i.e. LARC).

A network of generalist and specialist providers with clearly defined user care pathways is required to meet the contraceptive needs of the population in an effective and comprehensive manner. In the UK, lack of recognition of the role of specialist community contraceptive services in complementing general practice provision is leading to lack of investment and indeed disinvestment by many Primary Care Trusts (PCTs). It is worrying that despite additional resources provided centrally for sexual health in recent years, locally these community contraceptive services are reporting reductions in funding and capacity and this vital area of public health care is being ignored. A survey published in August 2006 by the Independent Advisory Group on Sexual Health and HIV revealed that a substantial portion of the $£ 300$ million funding provided for sexual health services is not reaching frontline services, but being absorbed by PCTs and Strategic Health Authorities to cover deficits in health care budgets. ${ }^{13,14}$ Community clinics are staffed by trained providers and attempt to provide a full range of contraceptive methods, given the constraints of shrinking budgets. Importantly, they serve the needs of marginalised and vulnerable groups who often do not access mainstream health care provision. These open-access, walk-in clinics, often situated in deprived areas and open in the evenings to enable ease of access, are reporting closures and are turning away clients, including teenagers. 


\section{COMMENTARY}

Commissioners and PCTs, out of ignorance or under financial pressure, are overlooking the fact that these community contraception clinics provide around $80 \%$ of the training in contraception, including LARC methods, for all professionals currently providing contraceptive care. ${ }^{15}$ Their closure will not only have adverse effects on client choice but also on training, impacting adversely on the future quality of contraceptive provision. Shifting the Balance of Power, ${ }^{16}$ which moves responsibility for local service provision of services to PCTs, is resulting in the destruction of the fundamental structures for providing choice of access to clients and the training required to improve and maintain the quality of contraceptive care. The current financial situation in the NHS is adding to the significant disadvantage being experienced already by contraception and reproductive health services.

Though political commitment to contraception has been expressed in all national policy documents, the reality on the ground, being experienced by clients and clinicians, seems very different. Though sexual health remains a priority for the government, there has been a singular lack of local action in addressing key issues in contraception provision. Lack of a holistic approach in the implementation of the National Sexual Health Strategy and complacency regarding contraception provision can only result in undesirable social consequences such as increases in unplanned pregnancy and abortion rates.

\section{Lost opportunities}

Community contraception clinics are recognised as fulfilling a much wider role than just contraception, providing other diverse services related to sexual and reproductive health including sexual health education and promotion. Community contraception services and general practices trained in contraceptive care offer even greater potential for public health gains by integrating sexually transmitted infection (STI) care with contraception. Sexual health promotion and screening for infections such as chlamydia are already part of some community contraception services. These services are already demonstrating the ability to develop a cost-effective, holistic, sexual health skill mix, enhancing the role of nurses, pharmacists and other health professionals. With support and investment, they are well placed to contribute to the government's 48-hour target for accessing genitourinary medicine services. The further opportunity for transfer of gynaecology and other reproductive health services into the community, in keeping with the aims of Our Health, Our Care, Our Say: A New Direction for Community Services, ${ }^{17}$ whilst maintaining standards and patient safety, will be lost if the potential of these services is not better exploited.

\section{The future}

There are already anecdotal reports around the country of women having to seek private sector provision of LARC methods as access is restricted within the NHS. In future, we may well see true contraceptive choice becoming a luxury, available only to the affluent and empowered. If current trends in contraception provision in the UK are not addressed as a matter of urgency then single mothers, teenagers, migrants, refugees, sex workers and other marginalised groups who already experience social exclusion will face barriers to obtaining the more effective methods of fertility control. This will have very high personal and social costs for these women and, importantly, high economic costs to the NHS.

There needs to be a clear message from government and public health policymakers to PCTs on the 'short-termism' of limiting contraceptive choice and training. Results of the long-promised 'mapping exercise' of baseline contraception provision and training in England ${ }^{9}$ is needed as a matter of urgency. PCT performance in improving contraceptive services should be monitored, not just access to STI care. Improving access to the full range of contraceptive methods, increasing uptake of LARC methods, and increasing nationally accredited training for all contraception providers would be a welcome start.

Are our politicians and NHS structures being complacent about contraception? Is it because people requiring contraception are well people and are not in fact ill that provides a perception that there is no pressing medical necessity to prioritise this aspect of sexual health care? Sexual relationships are part of normal life and good, confident use of contraception is a vital issue for the overwhelming majority of people and not just for some. It is not only an essential public health issue; it is also one of the most cost-effective investments in public health because the outcomes from non-use of contraception place a far heavier financial burden on society and the public purse.

Statements on funding and competing interests

Funding. None identified.

Competing interests. None identified.

References

1 O'Sullivan I, Keyse L, Park N, Diaper A, Short S. Contraception and Sexual Health, 2004/5. London, UK: Office for National Statistics, 2005

2 McGuire A, Hughes D. The Economics of Family Planning Services. London, UK: Family Planning Association, 1994.

3 Laing W. Family Planning - The Benefits and Costs. London, UK: Policy Studies Institute, 1982.

4 Social Exclusion Unit. Teenage Pregnancy. London, UK: Department of Health, 1999.

5 Department of Health. National Strategy for Sexual Health and HIV. London, UK: Department of Health, 2001.

6 A Strategic Framework For Promoting Sexual Health in Wales. Cardiff, UK: National Assembly for Wales, 2000.

7 Respect and Responsibility. Strategy and Action Plan for Improving Sexual Health. Edinburgh, UK: Scottish Executive, 2005

8 Recommended Standards for Sexual Health Services. London, UK: Medical Foundation for AIDS \& Sexual Health (MedFASH), 2004.

9 Department of Health. Choosing Health: Making Healthier Choices Easier (Public Health White Paper). London, UK: Department of Health, 2004.

10 Faculty of Family Planning and Reproductive Health Care. Faculty Membership Survey. Survey prepared by Taylor Nelson Sofres, 2004.

11 National Institute for Health and Clinical Excellence (NICE). Longacting Reversible Contraception - The Effective and Appropriate Use of Long-acting Reversible Contraception. London, UK: NICE, 2005.

12 Armstrong N, Donaldson C. The Economics of Sexual Health. London, UK: fpa, 2005,

13 Sexual Health Independent Advisory Group on Sexual Health. Choosing Sexual Health - Where has the Money Gone? (Report). August 2006.

14 Faculty of Family Planning and Reproductive Health Care (FFPRHC) "Disinvestment in family planning clinics must stop.." states the FFPRHC (Press release). London, UK: FFPRHC, 2006.

15 Faculty of Family Planning and Reproductive Health Care (FFPRHC). Training Survey. London, UK: FFPRHC, 2004

16 Department of Health. Shifting the Balance of Power: The Next Steps. London, UK: Department of Health, 2002.

17 Department of Health. Our Health, Our Care, Our Say: A New Direction for Community Services. London, UK: Department of Health, 2006

\section{Visit the Faculty Website at: www.ffprhc.org.uk}

